\section{Too much power to the people}

RECTOR Ove Nathan of the University of Copenhagen is quick to show visitors a pitch-black cannonball hanging from the ceiling outside his office. The missile is a souvenir of the British bombardment of 1807 and the ensuing fire, which destroyed most of the university as well as much of the rest of Copenhagen. The onslaught was the Danes' punishment for siding with Napoleon.

That the university would be a target for

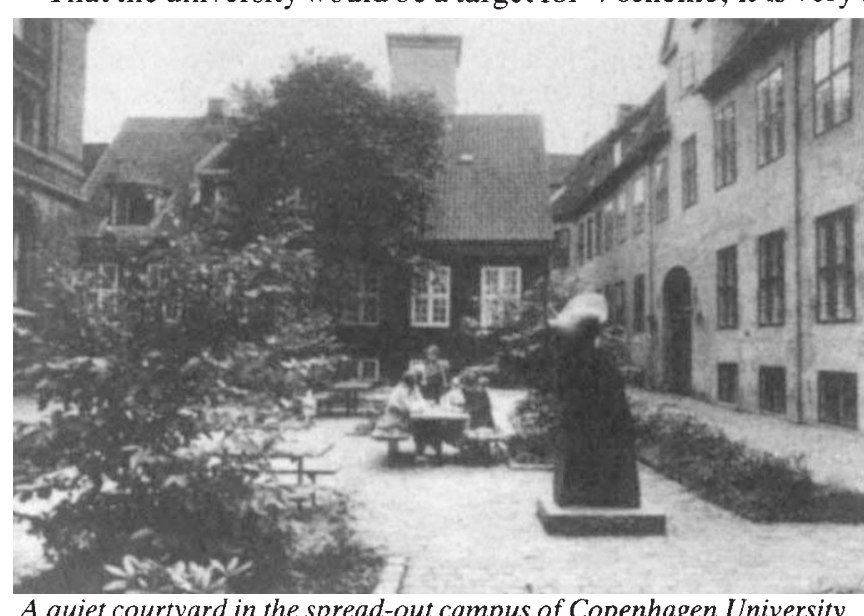

The other half is shared between faculty and the technical staff plus administration. Partly as a result of this development, politicians over the years have usurped as much authority as they could from the universities. When they want to initiate a programme, says Mogens Dahl of the Danish Research Administration, "they just create a new cigar box".

Under Copenhagen's democratic scheme, it is very hard to agree upon cutting personnel. Consequently, when hard times descended, says Dahl, "they didn't cut people, they just took away their pencils". Reduced operating budgets have made it difficult to maintain good research.

Nathan, like other rectors, now plans to "use the present law to its very limits in order to steer toward more research-oriented universities and more continuity in the cannons is fitting considering its central role in Danish intellectual society. Not only is Copenhagen University the country's largest educational institution, it is also the oldest, dating from 1479. Since then it has remained in the traditional continental mode, with five faculties, theology prominent among them. The other faculties are social sciences (which includes law and economics), humanities, medicine and natural sciences. Expansion has pushed most of the faculties away from the centre of the city.

Lately, another kind of battle has been simmering at the university. It is a tribute to Nathan that so few shots have been fired in the struggle over the allocation of limited government research funds. Says Lauritz Holm-Nielsen, director of the Research Academy (see previous page), "Nathan has done a lot in holding the diverse structures within the university together".

These "diverse structures", congenially called 'cigar boxes' by research administrators, make Copenhagen University an exceedingly difficult beast to manage. Not only is the structure atomized but administrators have very little power to change the system due to the legacy of the student movement in the late $1960 \mathrm{~s}$.

Student protests in Denmark were remarkably successful and resulted in a 1973 university reform roundly condemned for distributing power too broadly. According to the law, students have fifty per cent of the say in university policy decisions. decisions". To this end, Nathan wants to increase the rector's power from "essentially zero" by making some money available for strategic research planning and

\section{Århus University}

\section{Strength from competition}

All Danish universities operate under the same democratic university law, but some are more democratic than others. At Århus University democracy does not get in the way of doing good research. In physics, mathematics and molecular biology, the faculties at Århus are said to be the best in Denmark, no small feat considering the competition in Copenhagen.

The healthy rivalry dates back to 1928 , when Århus University was founded. It was the first Danish university outside Copenhagen and was private until as recently as 1970 . Its 13,000 students are divided among five faculties of which natural sciences has 2,500 .

What accounts for the relative lack of bureaucracy at Århus University besides its being far from the capital? Says Lauritz Holm-Nielsen, former dean of the faculty of sciences and currently director of the Danish Research Academy, "Democracy doesn't mean that no one takes responsibility; it just prescribes a system for electing people to take responsibility". Deans are stronger in Århus than in Copenhagen, he continues, and do not live in fear of being pushed out in the next elec-

\section{What's in a title?}

THE Danish Licentiat, granted for a thesis based on three years research following completion of the six-year Kandidatgrad, a Danish master's degree, is the equivalent of a PhD. But the difference in title causes difficulties for Danish students when they try to study abroad.

Since foreign study is such an important part of the Danish education, Copenhagen University's rector, Ove Nathan, and others are trying to rename the Licentiat, while creating uniformly high standards at all Danish universities to conform with a "good US PhD".

The traditional Danish Doktorgrad will not be affected. Getting a Doktorgrad involves five to ten years of independent work beyond the Licentiat. It is similar to the German Habilitation or the French Doctorat d'état, which has been abolished. The Doktorgrad confers no tangible benefits, says Nathan, with one exception. A Doktor may not be denied the right to give a public lecture at a university. This right is only exercised "when people get really mad at each other".

development. This would give him the opportunity "to secure the marginal additions [to the research budget] that we all know are so important". The rectors of all the Danish universities will meet with Education Minister Bertel Haarder on 26 November to present their recommendations. tion. When he was Dean in the 1970 s, Holm-Nielsen made sure that operating costs for research groups were not reduced, even when it meant not hiring the full complement of staff.

Holm-Nielsen also credits former dean Svend Bundgaard both for keeping more central authority in the hands of the Århus deans and for encouraging foreign study. "Århus has a tradition", he explains, "that you can't get a faculty position unless you've been abroad".

Århus physicists will benefit from a dual-purpose synchrotron now being constructed. It will be unique in storing both heavy ions (from protons up to actinides) and electrons, albeit not simultaneously. The physics faculty is planning to use the facility, which will operate in the $\mathrm{MeV}$ range, for six months at a time in each mode. The synchrotron may provide opportunities for industry, for example in microlithography, but the first nonphysicist collaborators are likely to be chemists and even biologists. There is discussion of building an X-ray microscope similar to that in Daresbury, England or at DESY in Hamburg. 